ERNEST $\square R L A N D D$ LAWRENCE BERKELEY NATIDNAL LABDRATDRY

\title{
Modification of Cathodic Arc Deposition Profiles by Magnetic Multicusps
}

S. Anders, R.A. MacGill, S. Raoux, RECEIVED and I.G. Brown Accelerator and Fusion Research Division

April 1996

Presented at the

17 th International Symposium

on Discharges and Electrical

Insulation in Vacuum,

Berkeley, CA,

July 21-26, 1996, and to be published in the Proceedings

DSTRIBUTION OF THIS DOCUMENT IS UNLMTEO 


\section{DISCLAIMER}

This document was prepared as an account of work sponsored by the United States Government. While this document is believed to contain correct information, neither the United States Government nor any agency thereof, nor The Regents of the University of California, nor any of their employees, makes any warranty, express or implied, or assumes any legal responsibility for the accuracy, completeness, or usefuiness of any information, apparatus, product, or process disclosed, or represents that its use would not infringe privately owned rights. Reference herein to any specific commercial product, process, or service by its trade name, trademark, manufacturer, or otherwise, does not necessarily constitute or imply its endorsement, recommendation, or favoring by the United States Government or any agency thereof, or The Regents of the University of Califomia. The views and opinions of authors expressed herein do not necessarily state or reflect those of the United States Government or any agency thereof, or The Regents of the University of California. 


\section{DISCLAIMER}

Portions of this document may be illegible in electronic image products. Images are produced from the best available original document. 
LBL 37948

UC 426

Paper to be presented at the

17th International Symposium on Discharges

and Electrical Insulation in Vacuum

Berkeley, July 1996

\title{
MODIFICATION OF CATHODIC ARC DEPOSITION PROFILES BY MAGNETIC MULTICUSPS
}

\author{
Simone Anders, Robert A. MacGill, Sébastien Raoux, \\ and Ian G. Brown \\ Lawrence Berkeley National Laboratory \\ University of California \\ Berkeley, CA 94720
}

April 1996

This work was supporled by the Flectric Power Rescarch Instilute under Award number 8042-03, by the U.S. Army Research Office under Award No. AROI18-95. and the U.S. Department of Energy. Division of Advanced Energy Projects. under contract No. DE-AC03-76SF00098. 


\title{
MODIFICATION OF CATHODIC ARC DEPOSITION PROFILES BY MAGNETIC MULTICUSPS
}

\author{
Simone Anders, Robert A. MacGill, Sébastien Raoux, and Ian G. Brown \\ Lawrence Berkeley National Laboratory, University of California, Berkeley, CA 94720
}

\begin{abstract}
The deposition profile of a cathodic arc plasma source with and without magnetic macroparticle filter has been measured using a deposition probe technique. It has been found that the profile is close to a Gaussian and that the width of the profile depends on the cathode material It was found that the dependence on the cathode material leads to a considerable radial variation of the elemental composition of the film when an alloy cathode is used. A magnetic multicusp field (magnetic bucket) near the exit of the plasma source or the magnetic filter was applied to flatten and homogenize the deposition profile.
\end{abstract}

\section{INTRODUCTION}

Cathodic arc deposition without and with magnetic macroparticle filtering has been used to form metal, oxide, nitride, or amorphous hard carbon films $[1,2]$. The thickness profile of the deposited films is given by the plasma density distribution and the position of the sample with respect to the plasma source. The plasma distribution is an important parameter which determines homogeneity of the deposition, maximum sample size, and deposition rate. It is given by the original plasma distribution of the vacuum arc influenced by anode and cathode geometry, and possibly modified by external magnetic field.

In the present paper we report on measurements of the plasma distribution of various cathodic arc deposition systems such as plasma sources without additional magnetic field, plasma sources with additional magnetic field magnetic macroparticle filter. A magnetic multicusp arrangement (magnetic bucket) is described which can be applied to all these systems for flattening the deposition profile and homogenizing the elemental composition of the plasma.

\section{PLASMA SOURCE}

For all experiments described in the next sections we have used a plasma source consisting of a $6 \mathrm{~mm}$ diameter cathode surrounded by a cylindrical anode. The arc current was 50-300 A, the arc duration $5 \mathrm{~ms}$, the repetition rate $1 \mathrm{~Hz}$, and the arcs were triggered by a high-voltage surface discharge. The source is described in detail in [3].

The plasma density distribution was determined by depositing a semitransparent metal film on a transparent substrate (polyester, $125 \mu \mathrm{m}$ thick).
The thickness of the deposited film was determined by measuring the absorption of the film as a function of the position using a HeNe laser set-up. The film thickness was calculated by a numerical solution of the Fresnel equations assuming a two layer system taking transmission, absorption, and reflection into account [4]. The optical constants of the metals and polyester were taken from [5]. A Langmuir probe was used to check the accuracy of this method, and very good agreement was found between the Langmuir probe measurements and the absorption method [6].

Fig. 1 shows the normalized film thickness as a function of radial position for various cathode materials at a distance of $9 \mathrm{~cm}$ from the source measured at an arc current of $160 \mathrm{~A}$.

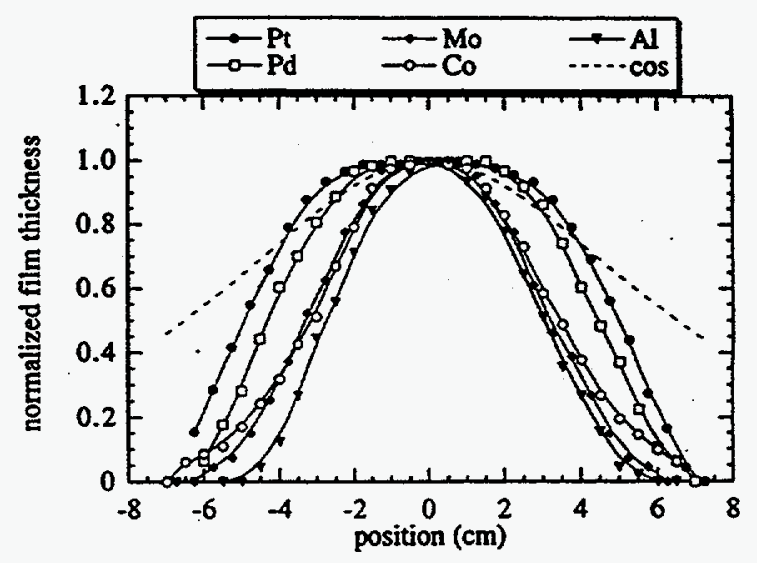

Fig. 1: Normalized film thickness for various cathode materials. Distance from plasma source $9 \mathrm{~cm}$, arc current $160 \mathrm{~A}$.

The width of the distribution is different for the different cathode materials. It also differs remarkably from a cosine distribution which has been reported for vacuum arc plasmas for geometries which are more typical for vacuum arc current interrupters (two opposite electrodes of equal disk-like shape, e.g. [7]). More recent papers describe the plasma distribution of systems closer in geometry to cathodic arc deposition devices, and they describe the distribution rather to be of Gaussian shape, peaked in the center [8].

Fig. 2 shows the widths (FWHM) of the distribution for various cathode materials taken from Fig. 1. There is a tendency for heavier elements to have a broader distribution. 


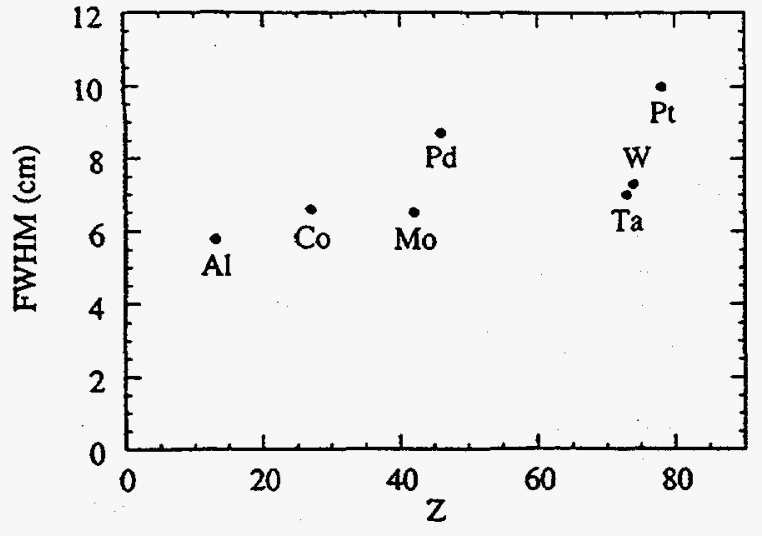

Fig. 2: Width of the plasma distribution (FWHM) for various cathode elements taken from Fig. 1.

\section{FILTERED CATHODIC ARC DEPOSITION SYSTEM}

The plasma source described in the previous section was connected to a magnetic macroparticle filter. The filter consisted of two solenoids, one straight solenoid of 10 turns around the anode to focus the plasma, and a $90^{\circ}$ bent free-standing solenoid of 25 turns with a major radius of $12 \mathrm{~cm}$ and a minor radius of $4 \mathrm{~cm}$. The solenoids were both in series with the arc current producing maximum magnetic field strength of $75 \mathrm{mT}$ at the cathode surface and $50 \mathrm{mT}$ within the magnetic macroparticle filter. Fig. 3 shows the normalized film thickness at a distance of $9 \mathrm{~cm}$ from the filter exit measured at an arc current of $300 \mathrm{~A}$.

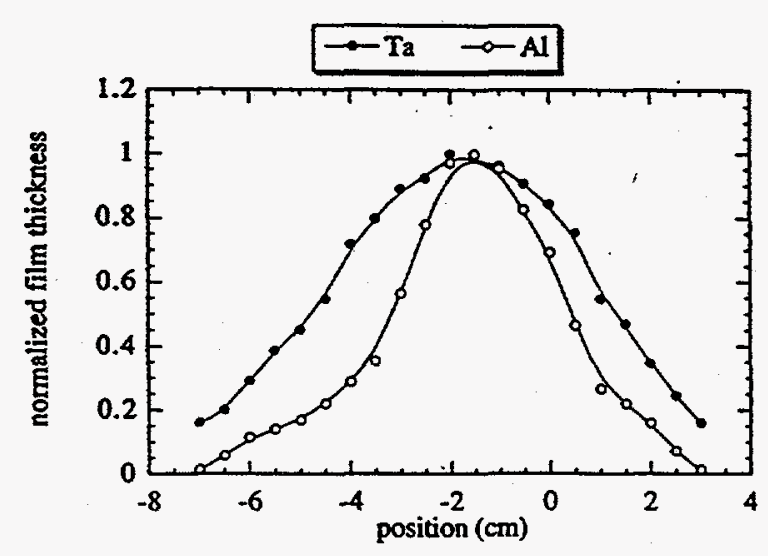

Fig. 3: Normalized film thickness for filtered cathodic arc deposition system. Distance from the filter exit of $9 \mathrm{~cm}$, arc current $300 \mathrm{~A}, \mathrm{Ta}$ and $\mathrm{Al}$ cathode.
The peak of the distribution is off-axis, shifted to the outer wall of the filter. This has been observed in earlier measurements using a Langmuir probe [9]. It is asymmetric and has a different width for $\mathrm{Al}$ (smaller) and $\mathrm{Ti}$ (broader).

Other authors have observed no shift [10], or a shift inwards or outwards depending on the magnetic field strength, and shifts also perpendicular to the plane of symmetry [11].

A shift from the axis is not a great problem for a cathodic arc deposition system as long as the center of the distribution is the same for every cathode material. Usually it is possible to locate the substrate in the center of the distribution and obtain a depostion profile peaked in the center of the substrate. What is a problem is the different width of the distribution for different elements. When an alloy cathode is used to deposit an alloy film, the effect of different widths of the distribution for the different elements leads to a separation of the elements in the plasma and to a very inhomogeneous elemental distribution in the film. Lighter elements have a higher fraction in the center of the deposition whereas heavier elements have a higher concentration at the edge.

Fig. 4 shows the fraction $x$ of $a \mathrm{Nd}_{1.0 \mathrm{Fe}}$ film deposited using a $\mathrm{Nd}_{1.0} \mathrm{Fe} 7.0$ cathode as a function of the distance from the sample center. The film was deposited using the filtered cathodic arc system at an arc current of $300 \mathrm{~A}$ and a distance of the sample (Si wafer) to the source of $5 \mathrm{~cm}$. The total film thickness was $300 \mathrm{~nm}$, and the film composition was determined by Rutherford backscattering spectrometry (RBS). The increase of the heavy element Nd toward the edge of the sample reflects the fact that heavier elements have broader distributions. The film thickness varied by $25 \%$ over a range of $1.5 \mathrm{~cm}$.

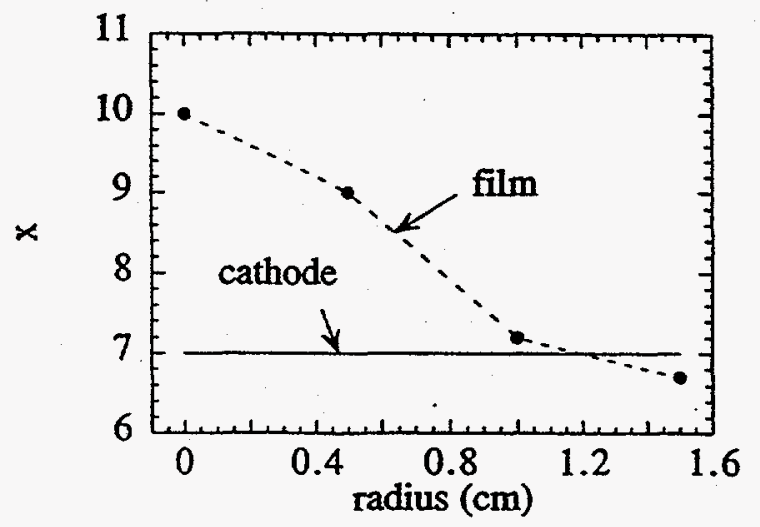

Fig. 4: Fraction $\mathrm{x}$ of a $\mathrm{Nd}_{1.0} \mathrm{Fe}_{\mathrm{x}}$ film as a function of the distance from the sample center. 


\section{APPLICATION OF MAGNETIC MULTICUSP FIELD}

In gaseous plasma sources a magnetic multicusp arrangement is often used to homogenize and flatten the plasma distribution [12-14]. This approach has been adapted to cathodic arc deposition systems. We explored two different sizes of multicusp "homogenizer" which could be attached to the exit of the plasma source or the magnetic macroparticle filter. The small multicusp (or "magnetic bucket") consisted of a steel tube of $8 \mathrm{~cm}$ length and $13 \mathrm{~cm}$ diameter, the large one of $8 \mathrm{~cm}$ length and $22 \mathrm{~cm}$ diameter, to the inside wall of which SmCo magnets were arranged to form a multicusp magnetic field configuration, 10 magnets for the small multicusp, 30 magnets for the large one. The magnets were $2 \mathrm{~cm}$ thick, and the region of the strong magnetic field reached about 2.5 $\mathrm{cm}$ into the plasma region. This results in an almost field-free inner region for the small multicusp of $4 \mathrm{~cm}$ and for the large multicusp of $13 \mathrm{~cm}$ diameter.

Fig. 5 shows an end view of the large homogenizer and schematically the distribution of the plasma in it.

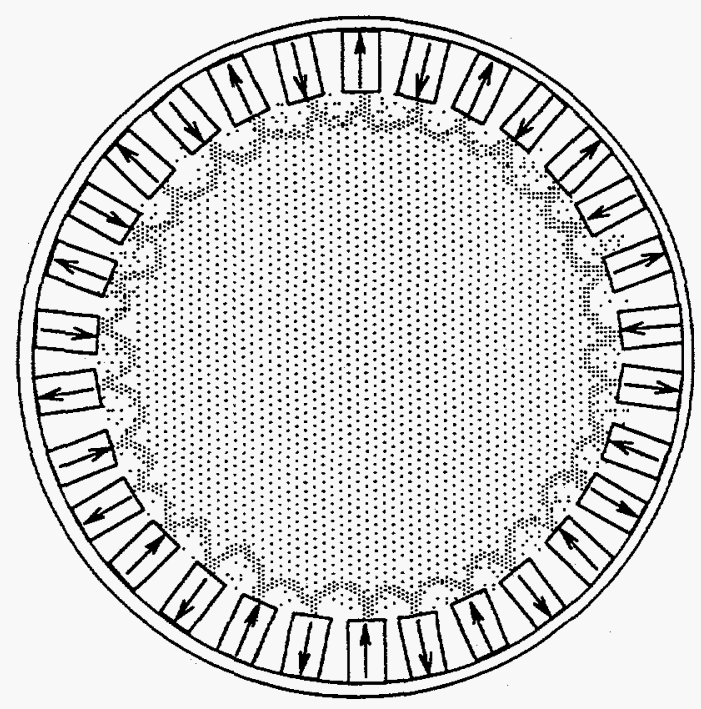

Fig. 5: End view if the large magnetic multicusp with schematic plasma distribution.

Fig. 6 shows schematically the relative position of the plasma source, the multicusp and the transparency. In a similar way the multicusp could be connected to the exit of the macroparticle filter. The plasma distribution within the bucket is shown in Fig. 7 (large bucket); this is a Ti film deposited at $300 \mathrm{~A}$ using an arrangement as shown in Fig. 6.

Fig. 8 shows the deposition profile using the plasma source with focusing solenoid with and without magnetic multicusp. A Ti cathode was used for the deposition; the source was opcrated at $300 \mathrm{~A}$. The distance between the source and the multicusp was $9 \mathrm{~cm}$, and the transparency was located at the exit plane of the multicusp.
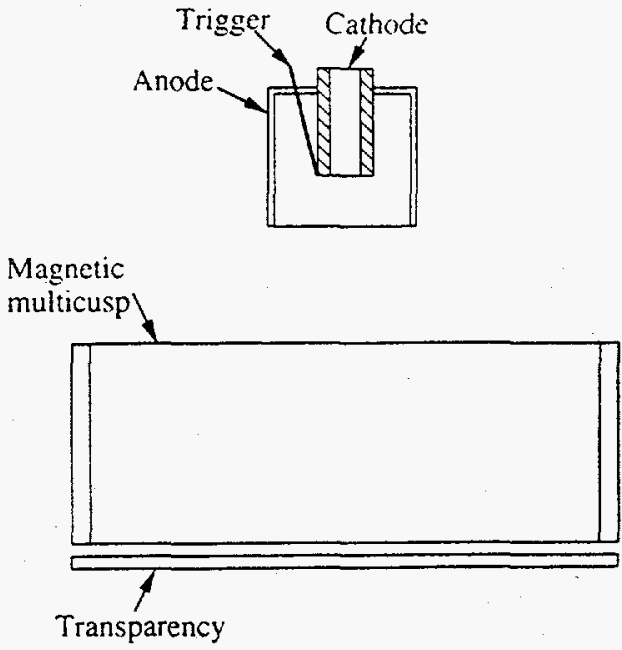

Figs. 6: Schematic drawing of experimental arrangement consisting of plasma source, multicusp, and transparency.

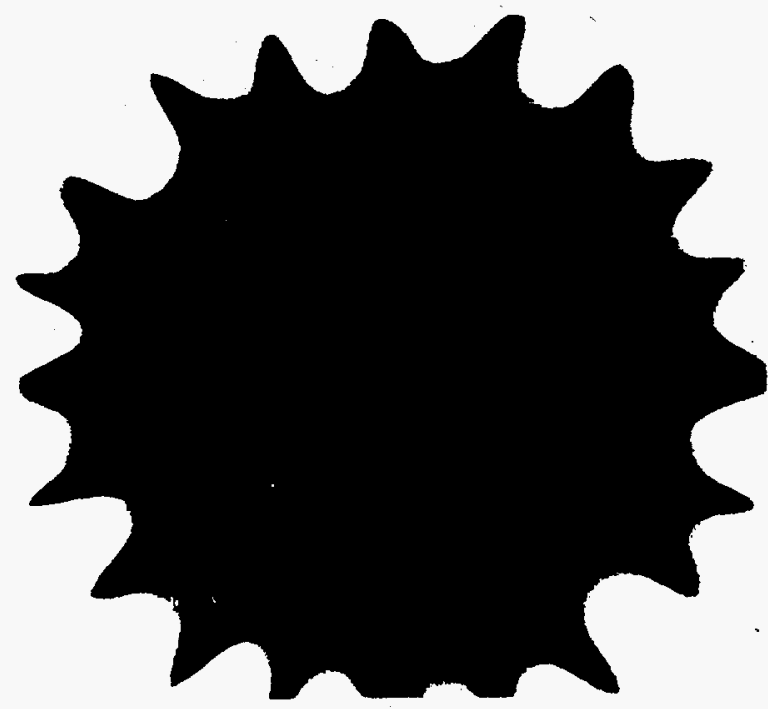

Fig. 7: Plasma distribution within the large magnetic bucket.

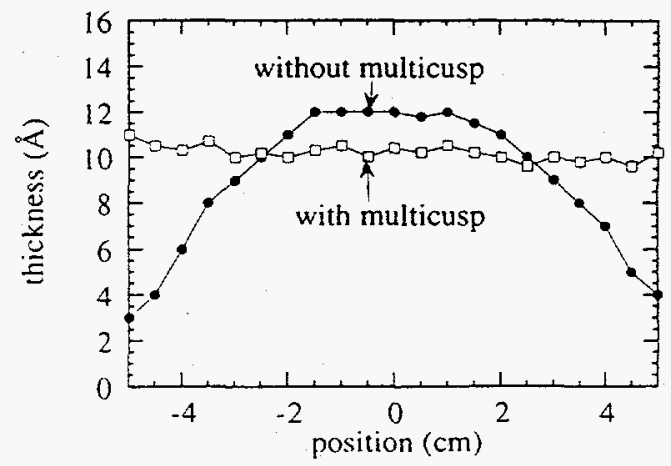

Fig. 8: Deposition profile with and without magnetic multicusp connected to the plasma source. 
The figure demonstrates the effect of the magnetic multicusp on the plasma profile. The profile is flattened, the deposition rate is slightly lower in the center and higher at the edge in comparison to a deposition without multicusp. This is clearly beneficial for a film deposition.

Figs. 8 and 9 show the deposition profiles when the small and large multicusp were used together with a filtered cathodic arc system.

Different cathode materials were used, the multicusp was at a distance of $6 \mathrm{~cm}$ from the filter exit, and the transparency in the multicusp exit plane. The arc current for the deposition was $300 \mathrm{~A}$. The profiles for different cathode materials are very similar. For the small multicusp (Fig. 8) the profiles are also flat over the inner area of the multicusp magnetic field arrangement, whereas for the large multicusp the rate is still somewhat higher in the center than at the edge. This can be improved by increasing the distance between filter exit and multicusp (which will also reduce the deposition rate).

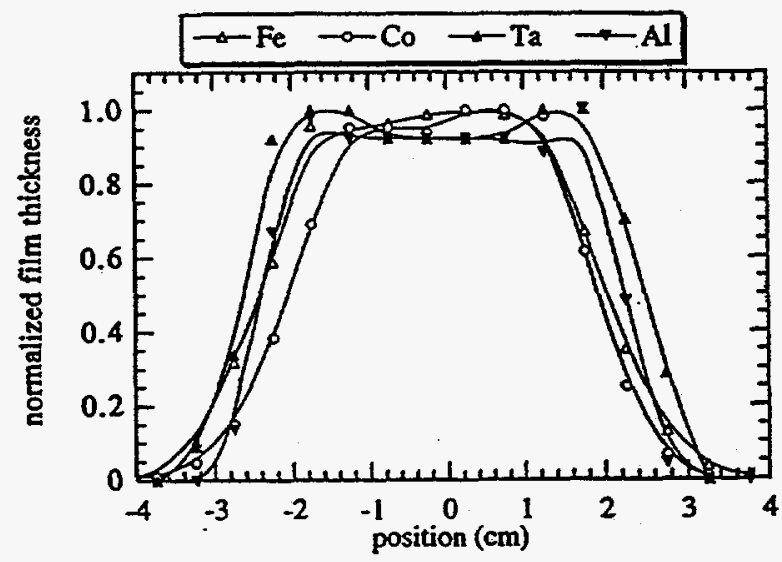

Fig. 8: Normalized film thickness for $\mathrm{Fe}, \mathrm{Co}, \mathrm{Ta}$, and Al. Filtered cathodic arc system and small multicusp.

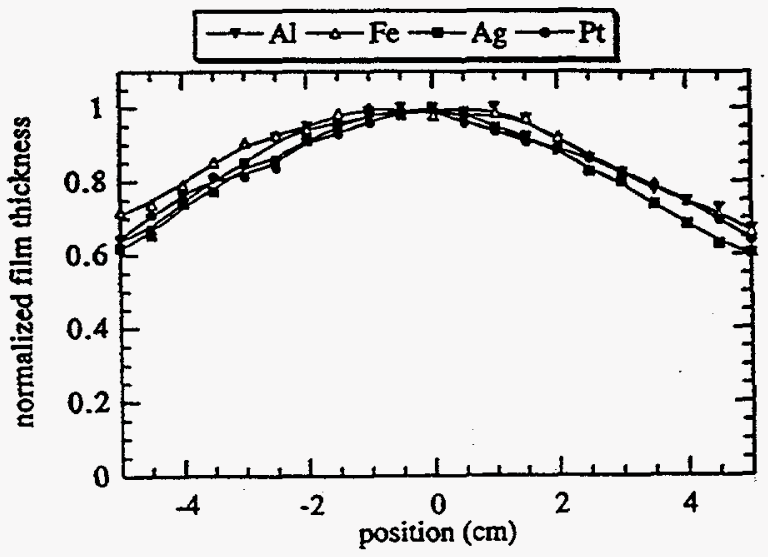

Fig. 9: Normalized film thickness for $\mathrm{Fe}, \mathrm{Ag}, \mathrm{Pt}$, and Al. Filtered cathodic arc system and large multicusp.
A further proof for the beneficial use of the multicusp field was the deposition of an alloy film similar to the one described in Section 3, Fig. 4. An alloy cathode with a composition of $\mathrm{Nd}_{1.0} \mathrm{Fe}_{4.4}$ was used to deposit an alloy film on a Si substrate. The filtered cathodic arc system equipped with the small multicusp at a distance of $5 \mathrm{~cm}$ from the filter exit was used for the deposition of a $180 \mathrm{~nm}$ thick film. The composition of the film as a function of distance from the sample center was determined by RBS. Fig. 10 shows the fraction $\mathrm{x}$ for the $\mathrm{Nd}_{1} .0 \mathrm{Fe}_{\mathrm{x}}$ film. The film has the same composition as the cathode and is homogeneous within $2 \%$ over the measured distance of $1.5 \mathrm{~cm}$ from the center. The film thickness varied only by $5 \%$ over this range. This is a considerable improvement in comparison to the deposition without multicusp.

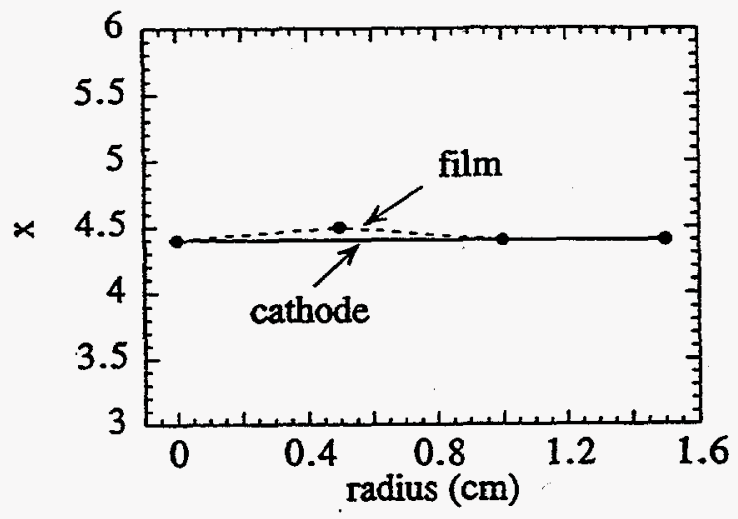

Fig. 10: Fraction $x$ of a $\mathrm{Nd}_{1.0} \mathrm{Fe}_{\mathrm{x}}$ film as a function of the distance from the sample center. Filtered cathodic arc system with small multicusp.

\section{CONCLUSIONS}

The plasma distribution for our cathodic arc plasma source was measured by an absorption method which was demonstrated to be a simple and reliable way of determining the plasma profile. The width of the profile varies with the cathode material, and this effect occurs for the source without and with macroparticle filter. This leads to a spatial separation of the elements when a deposition is performed using an alloy cathode. If the plasma is ejected from the plasma source or the filter into a magnetic multicusp of appropriate design, however, the plasma profiles are flattened and show the same shape for various elements. Depositions using an alloy cathode demonstrated that the compositional homogeneity of the thin film is greatly improved by the application of a magnetic multicusp plasma homogenizer. 


\section{ACKNOWLEDGMENTS}

This work was supported by the Electric Power Research Institute under Award number 8042-03, by the U.S. Army Research Office under Award No. ARO118-95, and the U.S. Department of Energy, Division of Advanced Energy Projects, under contract No. DE-AC03-76SF00098.

\section{REFERENCES}

[1] D. M. Sanders, D. B. Boercker, and S. Falabella, IEEE Trans. Plasma Sci. 18, 883 (1990).

[2] R. L. Boxman and S. Goldsmith, IEEE Trans. Plasma Sci. 17, 705 (1989).

[3] S. Anders, A. Anders, and I. G. Brown, J. Appl. Phys. 74, 4239 (1993).

[4] E. Hecht and A. Zajac, Optics, AddisonWesley Publishing Company, Menlo Park 1974.

[5] American Institute of Physics Handbook, MacGraw-Hill Book Company, 1972.

[6] S. Anders, S. Raoux, K. Krishnan, R. A. MacGill, and I. G. Brown, J. Appl. Phys., to be published

[7] C. W. Kimblin, J. Appl. Phys. 44, 3074 (1973).

[8] Y. Cohen, R. L. Boxman, and S. Goldsmith, IEEE Trans. Plasma Sci. 17, 713 (1989).

[9] A. Anders, S. Anders, and I. G. Brown, Plasma Sources Sci. Technol. 4, 1 (1995).

[10] I. I. Aksenov, S. I. Vakula, V. G. Padalka, V. E. Strel'nitskii, and V. M. Khoroshikh, Sov. Phys. Tech. Phys. 25, 1164 (1980).

[11] V. N. Zhitomirsky, L. Kaplan, R. L. Boxman, and S. Goldsmith, Surface and Coatings Technol. 76, 190 (1995).

[12] E. R. Ault and K. R. MacKenzie, Rev. Sci. Instrum. 44, 1697 (1973).

[13] R. Limpaecher and K. R. MacKenzie, Rev. Sci. Instrum. 44, 726 (1973).

[14] K. N. Leung, Rev. Sci. Instrum. 65, 1165 (1994). 